\title{
Evaluation of natural and social problems with DPSIR framework in Zagros forests decline, Iran
}

\author{
Mehdi Zandebasiri', Javad Soosani ${ }^{2}$ and Mehdi Pourhashemi ${ }^{3}$ \\ ${ }^{1,2}$ Department of Forestry, Lorestan University, Iran \\ ${ }^{3}$ Research Institute of Forests and Rangelands, Agricultural Research Education and Extension Organization \\ (AREEO), Iran
}

\begin{abstract}
In Sustainable Forest Management (SFM) combined evaluation of natural and social functions will do for protection of forest system. SFM implies management of forest resources without risking ability of future generations to meet their needs. Zagros forest in Iran, is considered as one of the largest habitats of plants in Iran. In this research, 7 sustainability indicators were prepared by the analyst team to evaluate SFM in Tange-Solak local area in Zagros forest. Then the main strategies of the key players in decline crisis management were determined based on collecting resources, documentary research and interviews with a team of Zagros forestry experts and the using of DPSIR framework (the model of Driving forces, Pressure, States, Impacts and Responses). Result of DPSIR framework shows that loss of knowledge of local communities traditional knowledge, not motivation in rural living in villages, inappropriate decision-makings for local residents and the lack of specialized work are the main forces related to Zagros forestry in forest decline.
\end{abstract}

KEY WORDS: CRISIS MANAGEMENT, FOREST SYSTEM, SMARTE D, DPSIR, FOREST DECLINE

\section{INTRODUCTION}

In Sustainable Forest Management (SFM) combined evaluation of natural and social functions will do for protection of forest system. SFM means management of forest resources bearing in mind the needs of the current generation without risking the ability of future genera- tions to meet their needs (Elbakidze, \&t Angelstam, 2007). The most common expression of these aspects are social, economic and environmental sustainability; however, creating sustainability is increasingly becoming challenging (Wang, 2004). One of the key problems is inability to have a common sustainability measurement tool. Since 1992, various Conferences and Sessions have been

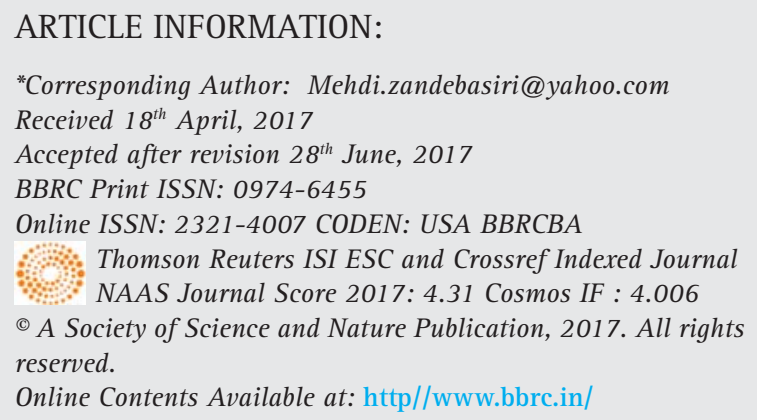


held to arrive at a unified criteria, that is, conditions and measures that indicate sustainable forest (Datta et al., 2010). Criteria selected for sustainability helps in determining a decision on what should be sustained; an indication of immeasurable overall condition. Performing and achieving a criterion is measured by an indicator. A particular indicator is a measurement tool of one aspect of the criteria. Indicators reveal the process of change with repeated measurements. A criterion is described and evaluated with a number of indicators related to it. These indicators are periodically controlled to evaluate the obtained results. The most analyzed issues and problems of SFM in Iran have been that of compilation and evaluation of criteria and indicators. SFM evaluation is considered after compiling criteria and indicators. It means designing a system for information feedback that will enable the monitoring of forest resources through its use (Zandebasiri \&t Parvin, 2012).

In SFM evaluation, current values of SFM indicators are compared with a set of reference values in sustainability indicators to achieve information on feedback process. Feedback process guarantees the life of system; hence systems without a feedback process will definitely die. Therefore, SFM evaluation is essential for the life of sustainable management system or in other words to ensure permanent functions of forests. (Wolfslehner and Vacik, 2011). Zagros are considered one of the largest habitats of plants in Iran. Zagros vegetation region is located in the West and Southwest of the country of Iran. Nowadays, these forests are in severe quantitative and qualitative danger due to the following: climatic reasons, uncontrolled exploitation, overgrazing of livestock, and lack of knowledge about management requirements (Pourhashemi et al., 2013). The people living in these forests have complex and difficult lives when compared to those living in other parts of the country (Imani Rastabi et al, 2015). Traditional exploitations to meet the needs of local communities are common in almost all of the Zagros forests, despite the objections of the executive management (Ghazanfari et al., 2004). These forests play an important role in water, soil and ecological balance management of the region.

\section{MATERIAL AND METHODS}

\section{STUDY AREA}

The examined local area is the catchment of Tange-solak in the province of Kohgilouye and Boyerahmad. Tangesolak forest is located in Likak city, which is approximately $15 \mathrm{~km}$ south of Kohgiloye and Boyer Ahmad province. This forest has an area of 1000 hectares. There are also agricultural and horticultural lands in this region. The main agricultural products include wheat and barley. Also, natural cypress trees form unique stand of cypress-oak. The existing forest has a high scientific value and it can be called living fossil. Most people residing here have relocated from the region due to lack of facilities and low income. While the rest of them left behind do not have permanent residence in the forest; these migrate to tropical regions in the period of October to late winter. In the current situation, forest preservation plan is applied for the region with a focus on forest resources protection by the executive management. The people still living here get drinking water from a spring which is in Tange-solak itself. Effect of dieback and decline has started in the region in previous years.

\section{METHODOLOGY}

For the evaluating of natural problems we created SMARTAD (Specific, Measurable, Available, Realistic, Time specific) indicators for SFM and for the combined evaluating of natural and for the study of social problems to SFM indicators and reaction of system to these problems we created DPSIR framework (the model of Driving forces, Pressure, State, Impacts and Responses). In the first section of the research, sustainability indicators based on the SMARTED framework were prepared by analysts to evaluate SFM.

\section{INTRODUCTION TO SMART\&D FRAMEWORK}

Based on the SMARTED framework, a performance evaluation indicator in a system should have the following characteristics (Davis et al., 2001):

A. being Specific (S) implies that the indicator must be special, determined and specified. In other words, an indicator must be comprehensive and preventive, transparent, simple, clear and expressive in such a way that it creates same interpretation of indicator's concepts.

B. being Measurable (M) implies that the indicator must be measurable. In other words, evaluation of indicators must be easily possible.

C. being Achievable (A) implies that the intended indicator must be achievable.

D. being Realistic $(R)$ implies that the indicator must be realistic. In other words, the indicator must be related to mission and organizational strategies.

E. being Time framed (T) implies that the intended indicator must have a specified evaluation period.

F. being a Database (D) implies that the required data and information related to an indicator 
must exist for the intended indicator. Through preliminary examinations by the team of analysts, it became obvious that key indicators of Near East process in this region falls short of necessary conditions for the above mentioned framework. Specifically, most of them were not a database. Therefore, 7 indicators of ecosystem features were provided for SFM evaluation. In the second section of the research the main strategies of the key players in decline crisis management were determined based on collecting resources, documentary research, interviews with a 3-member team of Zagros forestry experts and the use of DPSIR framework.

\section{INTRODUCTION TO DPSIR FRAMEWORK}

Due to the need for long-term consultations in this section, lower number of experts and interview method instead of questionnaire were used. After determining the strategies and using the analyst team analysis, a set of advantages for each of the strategies were presented. DPSIR framework has been provided by the Europe Department of the Environment development from the models of "the reason and the response". In 1970, Anthony Friend provided the Pressure-State-Response (PSR) model which received more attention compared to other methods such as index of sustainable economic welfare which was raised at that time because it examined a combination of social and economic problems. Then The United Nations Commission on sustainable development selected the framework of Driving forcesStatus -Response (DSR) in which pressure was replaced by driving forces in order to consider pressure reasons which mostly arose from the people and social problems.

Ultimately Department of Environment of Europe provided Driving force - Pressure - Situation - ImpactsResponse model from the expansion of two PSR and
DSR models. Based on the theory of DPSIR framework, a set of driving forces (political, economic and social activities) cause pressure and affect condition (Physical, chemical or biological), this leads to the ecosystem's response. DPSIR is a framework that is interconnected like catenary. The following figure shows a conceptual model of DPSIR framework.

\section{RESULTS}

The result SFM indicators showed the number of stages, density of number per hectare, numbers of trees per hectare with a healthy crown average height of pile, litter depth in millimeters, canopy cover percentage, average number of species in each plot, as well as regeneration level in hectare per square meter were identified as capable indicators of SMARTED.

The results of the DPSIR analysis showed that 2 groups of stakeholders meaning the executive management (Forest organizations, Rangeland and Watershed Management of the country and the General Directorate of Natural Resources) and the local community are the main players of forest decline and crisis management in Zagros forests. The result of the second section of the research in DPSIR analysis has been shown in figure 2:

\section{DISCUSSION}

The results of the DPSIR model evaluations revealed the most important Executive Management Strategies are protection of forest resources and saving rainfalls. Thus, strategies for cooperation and non-cooperation was considered for the local community in accordance with these strategies. Result of driving forces shows that loss of determining indigenous knowledge of local communities, not promoting living in villages, inappropriate decision-makings (Ghazanfar et al., 2004) and the

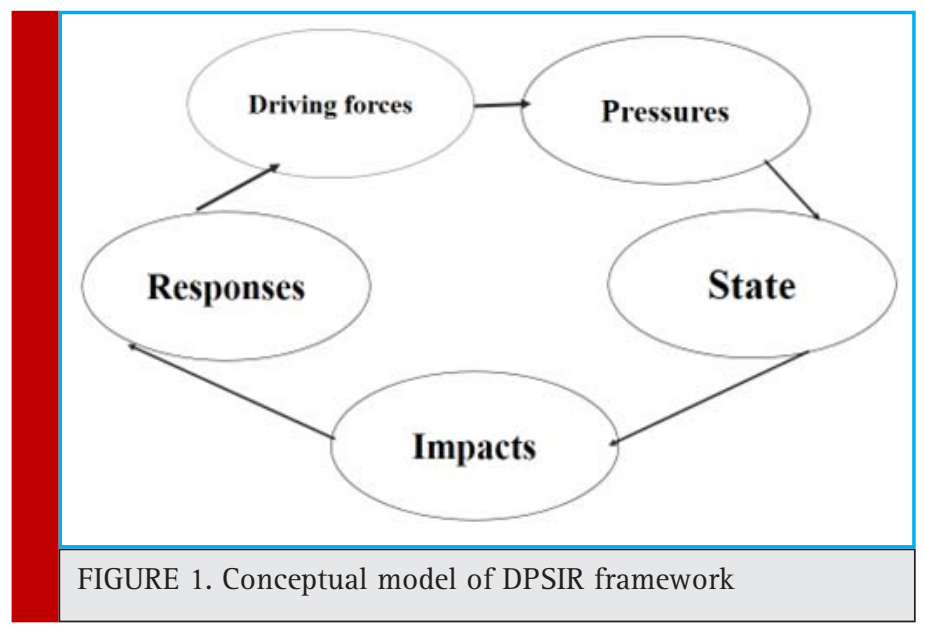




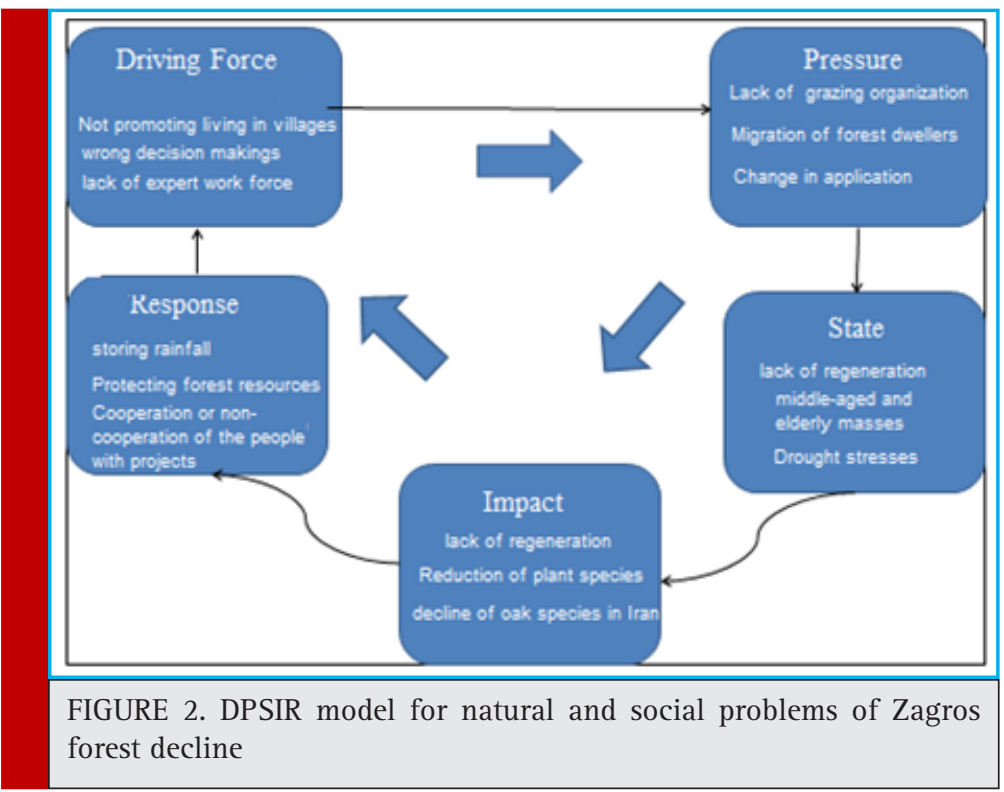

lack of specialized work force related to Zagros forestry (Zandebasiri \&t Ghazanfar, 2010; Imani et al., 2015) are among driving forces in forest decline. The lack of regulation (Pourhashemi et al., 2013) of livestock grazing in the forest, forest fires, migration of local residents (Zandebasiri \&t Parvin, 201) and increasing industrialization in the due to migrations as well as increased pressure of greenhouse gases and changes in land use are pressure forces in forest decline.

Sensitivity oak species in Iran to forest decline, lack of reproduction, soil erosion and protrusion of rock in most of the region, middle-aged and elderly trees (pourhashemi et al., 2013), clutter on the diagonal floor structure, movement of Arabic dust and global warming are among some of observable issues in status of examined region. Regeneration crisis, reduced number of plant species, reduced canopy cover percentage, soil erosion crisis and oak decline are among some of the effects of deterioration in the examined region. Saving rainfalls, protection of resources as a means of protection of forest resources are proposed management strategies for Prohibiting and preventing the deterioration that the local community can choose to have cooperation or lack of cooperation in reaction to these responses. In this study, a set of useful indicators for SFM was compiled in characteristics of ecosystems using SMARTAD dynamic framework. Due to the breadth of evaluation indicators of SFM, indicators related to the management measures, socio-economic and organizational characteristics are expected to be studied in other examinations. Livestock grazing, traditional perceptions of local communities, lack of participation in decision-making processes have aggravated socioeconomic pressures (Ebrahimi Rostaghi, 2006). In this research, attempts were made to provide a quantitative method for evaluation of SFM; a method that can have many applications. The issue of forest certification and verification of thresholds for forest sustainability is one of these applications. Forest certification can be widely used for Zagros forests. Forests with SFM certificate can have more subsidies and support of the government, their forest communities can have more authority to act, their sub-products will be provided by standard signs and so on, which require other studies.

\section{REFERENCES}

Datta, D, Guha, P., Chattopadhyay, R.N. (2010). Application of criteria and indicators in community based sustainable mangrove management in the Sunderbans, India Ocean \& Coastal Management. 53: 468-477.

Davis, L.S.; Johnson, K.N.; Bettinger, P.S.; Howard, T.E. (2001). Forest Management: To Sustain Ecological, Economic, and Social Values, 4th ed.; McGraw-Hill Publication.

Ebrahimi Rostaghi, M. (2006), The role of policy-making and decision-making in protection of outside North forest's, Conference on protection of forests in sustainable forest management, Forestry Community of Iran, p: 137-151 (In Persian).

Elbakidze, M. \& Angelstam, P. (2007). Implementing sustainable forest management in Ukraine's Carpathian mountain: The role of traditional village systems, Forest ecology and management: 249: 28-38.

Ghazanfari H., Namiranian M., Sobhani H., Mohajer R.M. (2004). Traditional forest management and its application to encourage public participation for sustainable forest management in the northern Zagros mountain of Kurdistan province, Iran. Journal of Scandinavian Journal of forest research, 19: 65-71.

Imani Rastabi, M., Jalilvand, H. and Zandebasiri, M. (2015). Assessment of socio-economic criteria and indicators in 
monitoring of Kalgachi lordegan forest management plan, Iranian Journal of Forest and Poplar Research, 23 (2): 1-8 (In Persian with English abstract).

Pourhashemi, M., Panahi, P., Zandebasiri, M. (2012). Estimation of acorn production of gall oak (Quercus infectoria Olivier) in Baneh forests using Koenig visual method. Iranian J. Forest Poplar Research. 19 (2), 194-205 (in Persian with English abstract).

Pourhashemi, M., Panahi, P., Zandebasiri, M. (2013). Application of visual surveys to estimate acorn production of Brant's oak (Quercus brantii Lindl.) in northern Zagros Forests of Iran. Caspian Journal Environ. Science. 11: 85-95.

Wang, S., (2004)One hundred faces of sustainable forest management, Forest Policy and Economics. 6: 205- 213.
Wolfslehner, B. and Vacick, H. (2011). Mapping indicator models: from intuitive problem structuring to quantified decisionmaking in sustainable forest management, Ecological Indicators. 11: 274-283.

Zandebasiri, M., \&t Ghazanfari, H. (2010).The main consequences of affecting factors on forest management of local settlers in the Zagross forests (case study: Ghalegol watershed in Lorestan province), Iranian Journal of Forest. 2(2), 127138.

Zandebasiri, M. \&t Parvin, T. (2012). Investigation on importance of Near-East process,s criteria and indicators on sustainable management of Zagros forests (Case study: Tange-Solak watershed of Kohgilouye and Boyerahmad province), Iranian Journal of Forest and Poplar Research, 20(2): 204-216. 